\title{
Notes on a methodological discussion: autobiography, critique and time
}

\author{
Gunvor Løkken
}

Vestfold University College, Norway

\begin{abstract}
After having tried for some time to overview the contemporary field of qualitative research to give a lecture for a professorship in that area, my idea at the outset of writing this article was to address whether changes in qualitative research should be viewed as recurrent revolutions as highlighted by Denzin and Lincoln (2000; 2005), or as a field of continuing key themes and long-standing tensions, as conceptualized by Atkinson, Coffey and Delamont (2003). However, during my writing, after one detour into the May 2009 issue of Current Sociology and a second detour into the July 2009 issue of Qualitative Research, my attention focused on to how critical debate and review are displayed in different methodological positions of qualitative research. In my reading, the discussion in Current Sociology between main stream and postmodern methodological positioning revealed an utterly one-way feminist critique; this was also the case in one of three book reviews of The Handbook of Qualitative Research (Denzin and Lincoln, 2005) in the referred issue of Qualitative Research. My puzzle over this critical stance, and my third detour, into Yvonne Lincoln's discussion of twenty-five years of qualitative and new paradigm research in the January 2010 Issue of Qualitative Inquiry, helped evolve the following notes on a methodological discussion. The notes are partly structured by a temporal narrative over personally lived qualitative research, and partly by an epistemological narrative of a methodological discussion, interwoven with the passing of time when writing.
\end{abstract}

\section{Introductory autobiography}

When I was working with my Master's thesis in Early Childhood Education towards the end of the 1980's in Norway, qualitative methods was not included in the portfolio of research methods at my university. What we were taught in addition to historical methods, were statistics and other quantitative methods. I therefore had to read on my own the characteristics of qualitative methods, as presented for example by Michael Quinn Patton (1980), saying (p.121): 'Enter into the world. Observe and wonder, experience and reflect.' Indeed, I thought, as I was planning the inquiry of how relation and community among toddler peers come into being when meeting regularly in a Norwegian k indergarten (barnehage) context. With cues like hermeneutics and phenomenology, holistic perspective and inductive analysis, the choice of methods mainly was between naturalistic observation, depth interview and content analysis, listed with each method's advantages and disadvantages, and through which meaning was to be interpreted into and out of human interaction in cultural contexts. This was all about the researcher's empathetic comprehension on the basis of her or his subjective experience, and the same researcher's systematical analysis and arrangement of collected material, and the adherent interpretation and (re-)presentation. In the early eighties the method of group conversation was regarded as quite experimental in Norway ( eg Hoel and Hvinden, 1982). 
Even at the end of the 1990's, life as a qualitative researcher was relatively safe and sound through my theoretical and observational PhD-study (yes, still observational) of truly small body subjects (Løkken, 2000a). This was an inquiry based on my edification (Løkken, 2000b) of Merleau-Ponty's The phenomenology of perception (1962), on Adler and Adler's chapter on 'observational techniques' in The Sage Handbook of Qualitative Research (Denzin and Lincoln, 1994), on Riessman's Narrative Analysis (1993) and on Max van Manen's Researching Lived Experience (1997). In other words, this was before the postmodern 'excesses' of novelty prevailed the increasing new volumes of The Handbook in 2000 and 2005. The terms 'excesses' and even 'wild excesses of novelty' are not mine, but named by Atkinson, Coffey and Delamont (2003, p. x ). Among other possible interpretations, I read the latter as a commentary to The Handbook of 2000 , as it requires a reminder of the Key Themes in Qualitative Research.

When given the free choice of focus to lecture for a professorship in qualitative methods (Løkken 2008), the time had come for me to update and deepen my relationship to the debate about our canon, as comprehensively provided by Denzin and Lincoln $(2000,2005)$ and as introduced by Atkinson, Coffey and Delamont (2001), and followed by their book in 2003 on the key themes of continuity and change within the history of qualitative research.

\section{Handbook of qualitative research}

The proliferation of postmodern perspectives is celebrated by Denzin and Lincoln (2000; 2005) as projects of interpretation, critical perspectives on education, performanceethnographies, standpoint epistemologies, critical race theory, queer/critical/poetic/materialistic/feministic/reflexive ethnographies, British/German/USAcritical and transnational culture studies, variances of grounded theory, pluralistic ethnomethodological themes, and Afro-American, prophetic, postmodern and new pragmatic Marxism. Denzin and Lincoln identify the development of qualitative revolutions through eight periods of qualitative research:

(1) The traditional - up to 1940; (2) Modernism towards 1970; (3) Blurred genres towards 1985; (4) "Representation crisis" towards 1990, with more reflexive research and writing about gender, class and race; (5) "Triple crisis" in the 1990's with critical, interpretive, linguistic, feministic and rhetoric turns. After 1995 they name (6) postmodern experimentation; (7) postexperimental questioning; and (8) 2005 +futurism.

The apprehension spread after this is that lived experience happens only in the text of the researcher when writing and re-presenting his or her research. Therefore, direct access to other people's lived experience is no longer possible. According to postmodern and poststructural positioning there is no world 'out there' (Alvesson and Sköldberg 2008). As a consequence, validity, generalization, reliability - and alternative terms for this - must be rethought; which already was done according to Denzin and Lincoln (2005, p.19) in " postpositivist, constructionist-naturalistic, feministic, interpretive, performative, poststructural and critical discourses.'

At this point, after having made quite an effort to enter the researcher worlds of the 2000 and 2005 editions of The Handbook, I must admit that, in addition to questioning what a handbook actually is, I deliberately regressed to a very thin book by Patton (1987), containing the steady offer of How to Use Qualitative Methods in Evaluation. To cope with my researcher 'regression', the guiding question was:

- What was qualitative research and methods all about to begin with?

This question is partly answered above when summing up at the outset of my autobiography the characteristic underpinnings of qualitative research with reference to Patton (1980). In Patton's 1987 publication the methods of in-depth open-ended interviews, "direct" observation and content analysis are well arranged with explicit guidance to the different 
steps of the processes. However, those were the days; and looking back on them at this point of my inquiry made me catch my breath. Although I do not claim that a similar regression was at stake for Atkinson, Coffey and Atkinson when they found it was time in 2003 to revisit classical themes in qualitative research, the fact that they did so was also of great relief to my struggle for trying to overview the comprehensive field. As Denzin and Lincoln $(2000,2005)$ depict revolutions and representation crises within qualitative research, and warmly embrace the spread of postmodernism and (political) queer-, feministic and race inquiry, Atkinson et al. (2003) plead a somewhat cooler appraisal of the field, by revisiting what they see as key themes and principally basic continuities in qualitative research, rather than paradigmatic revolutions rejecting prior positions.

\section{Key themes in qualitative research}

What Atkinson, Coffey and Delamont (2003, p.xi) think is that it is time to cool down the more fevered writing about intellectual crises and over-emphasized methodological novelty within qualitative research. They argue that much of what is paid attention to in so called postmodernism, has long ago has been discussed, for example in interactionist sociology. They even call upon the notion of sociological amnesia to capture how contemporary sociologists, in search for novel ideas, tend to ignore the past and periodically reinvent the wheel. They make the point that, in the rush for ' new' ethnographies like auto-ethnography, narratives and voices, messy texts, postmodern theories and other ' wild' excesses of novelty, key themes in qualitative research are forgotten. They claim that when collecting narratives and life stories, we should not only reproduce them, but analyze their production, construction and cultural significance. Experimental writing should be done with the purpose of improving the reconstruction of the social world to expand our re-presentation of this world.

Being crisp in their critiques, Atkinson et al conclude with neither simple formulas of method nor proclamations of new periodical paradigms within the research field. They present more of an anti-conclusion, with less methodological ferment, less rush for novelty and methodology in itself. They urge us not to allow the qualitative (key) solidarity project of trying to take the Other's perspective be replaced by the private and personal problems of the researcher: 'We need to cultivate still the capacity to bracket our own identities and commonsense assumptions, not only to celebrate them as personal warrants of knowledge' (Atkinson et al. 2003, p. 190).

Although these authors truly do recognize that there have been remarkable changes in the writing practices of qualitative research, they see no need to go on referring to it as crisis of representation. They also claim that presentation of qualitative research has since long has been characterized by variation in styles of writing, from the most traditional to the most alternative and literary modes available. They caution against the danger of aestheticizing social phenomena through extreme self-conscious authorship and textual innovation. Ironically, they say (p.191) these tendencies have presented new ways of privileging the author. They claim that while the researcher-as-author was accused of presenting a hegemonic view, the textual experimentation of the ethnographer-as-author also may exercise a hegemonic relation to the reader as well as to the subjects of research. Atkinson et al maintain that ethnographical work should still give priority to the key theme of discovering and understanding 'other' social worlds, rather than self-absorbed reflections exploring and transforming the identity of the researcher.

Thus re-introducing some key themes in qualitative research, the three authors want us to pay respect to the 'Old Guard' of ethnography as well as the experimental (postmodern) ' Avant Garde' of the research field. In conclusion (p.199), they argue that rather than a developmental model of (post)conceptualization, they would conceptualize the field of ethnography in terms of continuing and long-standing tensions. Still, recurrent polarities are the tensions between 'scientific' and 'interpretative' inquiry, between 'realist' and ' 
experimental' texts, between impersonal and experiential analyses, tensions of which the two poles exist side by side.' Amid the disputes about the past, future, and present of ethnography we have consistently tried to steer a course between the wilder excesses of novelty and a stolid reactionary conservatism' (Atkinson et al. 2003, p. x). It now seems to be time to ask How is the field's climate for such a course between positions?

While elaborating further on this question in the first drafts of this article, I was alerted by the May 2009 issue of Current Sociology, featuring an article by Nigel Fielding. This is commented on and responded to by two opponents and closed down with Fielding's reply. The dispute indeed concerns the steering of a possible course between mainstream multiple methods and postmodernism. But even more, the dispute concerns how the critical views are displayed; in other words the climate or culture for academic critique that streams out of it.

\section{Building bridges or widening gaps?}

In his own words, professor in sociology Nigel Fielding (2009a) goes 'out on a limb' in his effort to show how what he calls moderate postmodernism can reconcile with mainstream multiple methods (triangulation). He argues that the difference between the two positions is surprisingly little. Drawing on postmodern approaches on the one hand and his own empirical examples of triangulation on the other, Fielding's main argument is that social science's orientation towards using multiple methods to increase analytical density and conceptual richness, rather than traditional validation, makes possible a reconciling approach between multiple methods and moderate postmodernism.

In the same issue, two well-oriented opponents within postmodern thinking respond to Fielding's article. Having read their responses, my attention was drawn to what I experienced as very different cultures of critical debate. In the first response, the philosopher Paul Healy (2009) recognizes both Fielding's attempt to identify affinity between the two positions and his great insight into the one of multiple methods. Healy goes on to confirm what they both agree on, but he wants more discussion of the epistemological and ontological grounds for postmodern thinking. Finally, Healy depicts changes that complement Fielding's concern for showing similarities between the positions, but without minimizing the similarities.

In the second response, the sociologist Celine-Marie Pascale (2009) concentrates on the question: How did a good idea go so wrong? She claims that Fielding has not read enough about postmodernism, and that he has not used enough of what he has read. She holds him responsible for having re-defined postmodern concepts to replicate modern thinking. All-in-all she concludes that Fielding has climbed the wrong tree to write 'out on a limb'. As we know, a second meaning of going out on a limb is to isolate oneself with unpopular meanings. So when isolating Fielding on the limb of what she defines as the wrong tree, Pascale apparently executes this second meaning.

The way I read the two responses, Healy's ways of displaying critique is:

- confirming agreement as well as showing disagreement

- pointing out strengths as well as shortcomings

- opening up for a dialogue about similarities as well as dissimilarities

- concluding on how the positions can inspire each other

In other (and still my) words, Healy's attitude, like Fielding's, is openness for bridging the two positions. The critique appears as balanced.

However, the topic of bridging seems resolutely closed down in the second response. In my reading, the critical remarks displayed here appear as:

- identifying errors by condemnation (Fielding's writing is insufficient and wrong) 
- accusation (Fielding 're-defines' to fit own ideas)

- total dismissal (Fielding has climbed the wrong tree to write out on a limb)

The attitude I find as pervading Pascale's response is not to find understanding for the possibility that ideas similar to postmodern ones may have existed before. In other words, she seems to pursue the wrongs and the nots. Moreover, she does not see Fielding's point that astonishingly little re-definition is needed to identify similarities between postmodern thinking and multiple methods applied the way Fielding emphasizes. As a consequence, since the good idea of the article is found to go so wrong, the critic is the one to stand out as knowing what is right. In my opinion, although postmodern thinking is usually wrapped with the rhetoric of pluralistic diversity and multi-faceted manifold, what paradoxically is identified in the discussion above is a rather one-sided and one-directional postmodern criticism. Thus, the critique appears as unbalanced.

Apparently , the choice of 'going out on a limb' was not accidentally chosen; it is Fielding's invitation to a dialogue about two positions. In closing down the discussion, Fielding concludes that research practices that solely strive for transformation, will end up boring. When the interest of novelty fades, the field will ask for more substance. A bridge between the two sides must have more substance than just being between, and will only serve its purpose if it is two-way (Fielding 2009b, p.465).

Having identified, through my gaze, these ways of displaying academic critique in current sociology, the main arising question now is:

\section{- What is it to be critical in academic work?}

Is it about identifying and balancing strengths and weaknesses in thoroughly constructed research contributions? And about seeing such constructions from several points of view that eventually can be bridged? Or is academic endeavor of being critical more about going straight to the one side of identifying and deconstructing insufficiencies and wrong thinking (!) in others' constructions? Is it perhaps defining deeper layers of the text that the author him/herself could not see was there? And ultimately taking part only on such premises? If so, what we face can be hegemonic arrogance.

At this point of the article, to avoid potential accusation of own arrogance, I surely should have gone thoroughly into critical (e.g. Marxist) theories concerned with the conflicts of interest in society, or into critical ethnography or cultural studies, or even more critical feminist/queer or race theory, to inquire for example what is meant by a theory of ' critical humility' claimed by Denzin and Lincoln (2008, p. 249) and outlined by Kincheloe and McLaren (2008). However, leaving that task as yet to come, I stick to my present notes that are mostly on the surface of a methodological discussion. In $\mathrm{n}$ the next section I consider reviews of Denzin and Lincoln's 2005 version of the SAGE handbook, and the ways these reviews are displayed.

\section{Critically (?) reviewing The Handbook}

Interestingly, the July 2009 issue of the nine year young journal of Qualitative Research brings three different reviews of the third edition of Denzin and Lincoln's Handbook of Qualitative Research (2005). The first reviewer Adam Drazin's main point (2009) is to recognize The Handbook as a key text that all qualitative researchers should have access to. But to him the size (1,288 pages) barely qualifies as 'handbook' and would take a two-year course to fully read. He also questions (p.383) that, as they do advocate diversity, Denzin and Lincoln put the qualitative project in the division for fighting 'forces of darkness' in what they see as a deeply divided a contemporary world of research. On the other side of darkness is a loosely-defined community sharing a qualitative research project which involves asking how the discourses of qualitative research (i.e. the research politics of the USA) can be used to help create and imagine a free democratic society. But although Drazin 
misses some papers on material culture and embodiment, his overall conclusion is that the book succeeds fairly well in what it is trying to do, but ironically enough as much by quantity as quality. When laying aside political claims and statements about bricolage as metaphor, Drazin finds the book well-founded and thought provocative in overviewing, considering and comparing highly contemporary methodologies. All together he points the book out as an important key text for why we do qualitative research the way we do. I read Drazin's displayed culture of critical review as a two-way balancing between pros and cons.

The second reviewer, Christina Hughes (2009), has read the book as ' 1288 pages of pure joy' (p.386). She thinks this edition continues in the tradition of its predecessors in being ' magnificently enticing and compellingly creative' In fact, the teacher and researcher are now 'almost spoilt for choice of good quality' and the book is found to constitute a 'phenomenal contribution to writing on qualitative methodologies' (p. 386 Hughes makes the point that the topics covered focus primarily on critical and post forms of methodology and 'indeed one catches (the editors') excitement at the creativity and challenges contained in the papers in this text' (p. 387). 'What more can one say' Hughes concludes, ' but recommend it to you wholeheartedly?' (p.388). I read Hughes' displayed culture of critical review as one way positive and partial.

However, when bridged with the third reviewer Maggie Gregory (2009), some balance in the feminist reviews of The Handbook can be seen as restored. (Here I read both Hughes and Gregory as feminist authors). On the one hand Gregory, like Drazin, comments on the 'daunting' volume of the book (p. 388), and on how several people told her they did not have time to read it in her course of 'touting' it about. This seemed to her as defeating the purpose of a handbook But on the other hand, while each edition has grown larger and the scope of each has been expanded, all three editions are needed, according to Gregory. She thinks they can be used to map significant changes in methodological thought in recent years. If the first edition (1994) was relatively conventional in subject-matter and structure, and the second (2000) reflected the kinds of change projected in the editors' narrative of changing 'moments' in research, then the third (2005) moves the debates further again, to incorporate explicitly political aspirations for qualitative research (p.389). Gregory's conclusion is that Denzin and Lincoln (2005) provide an invaluable synthesis of current thinking in ethnography.

What strikes me when comparing the critical debate on Fielding's article with the two first reviews of The Handbook, is that, while both the male critique appears as two-way balanced, the two female and feminist critiques appear as one-way unbalanced. Where Fielding's article in Pascale's critique was found mostly wrong, The Handbook can be read as saying what is right, given Hughes' ovation all through her review.

What do these contributions tell us about diverse ideas of what critical is? How come the differences in critical culture? Are they due to disciplinary traditions? Ideology?

Methodology? Gender? The individual person? Time? Probably all of this. Nevertheless, what unites the two more imbalanced one-way critics above, either positive or negative, surely are gendered postmodern orientations and articulated statements of what is wrong (and interpreted as what is right). On the other hand, being so oriented, an appropriate objection at this point of course can be:

\section{- Who said critical commentary and review should be balanced?}

At a time when we in Norway also experience a version of what Denzin and Lincoln (2005, p.9) label as 'Bush-science' with ' external demands for experimental, evidence-based, racist, masculine and quantitative epistemology', a simultaneous claim made by postmodern scholars on the other hand is that the world is put out of play by postmodern educational perspectives (Steinsholt and Dobson, 2009). The gap between the 'Bush' and the postmodern position seems infinite. However, I perceive an impetuous description of the (external) 'Bush'-side as well as a possessive positioning of the postmodern (in)-side. In 
other words, parallel to the frustrated outburst over the resurrection of hegemonic science in the 'Bush' version, postmodern perspectives seem to be ascribed the omnipotent power of putting the world out of play. The question arising next is:

- Will 'the world' allow postmodern educational perspectives to be that potent?

The time for cooling down the appraisals of new perspectives within field of qualitative research, as called for in 2003 by Atkinson et al, apparently continues. Do we and should we accept one-way streams of critics of particular political reasons? If the answer is yes and this becomes 'true' in the sense of politically correct, what happens then to the very idea of critical reflection? Is critical to be the art of defining 'the wrong', so as to lead us in 'the right' direction? Political correctness can overtake research adequate to policymaking, as well as research adequate to a selected paradigm.

I find the questions raised in this section crucial to the way Atkinson et al. (2003) challenge 'old' as well as ' new' qualitative researchers. In critical thought, both the Old Guard and the Avant Garde should have voices, especially if 'critical' also involves enhancing democratic practices. Therefore, to me pro and con constitute a vital criterion for what critical is. When also adding into this polar 'synthesis', a call for keeping in mind the more continuing key themes and longstanding tensions of qualitative research at the same time as we experiment and explore novelty, a somewhat balanced contemporary view of the field appears. Such dynamic balance is my view of what the critical can be.

\section{Conclusion}

The 'debate about our canon' as presented by Paul Atkinson, Amanda Coffey and Sara Delamont in the debut issue of the journal Qualitative Research (2001), invites the pursue of manifold through critical engagement with:

- the orthodox and the heterodox

- the familiar and the innovative

- the modern and the postmodern

- the traditional and the experimental

Unless the one side claims to be right, and the other to be wrong, it should be as 'simple' as letting both sides play rather than put out of play. Instead of the more partial either-or critical culture, for example of being solely positive to what seems to be 'the right paradigms' or solely negative to 'the wrong', critical to me ends up as identification and analysis of polarities allowed to exist simultaneously, as diverse sides often of the same matter. The critical task when facing polarity is not necessarily to synthesize, but rather to let thesis and anti-thesis mutually enrich, instead of excluding each other. If the advocated ideal of (postmodern) qualitative research is pluralistic manifold and diversity, I think I have identified through my discussion above at least two conditions of vital importance to such aspiration. First is the principle of simultaneously existing polarities, as followed by for example Atkinson et al. (2003), when they remind us about the continuing key themes in qualitative research and at the same time discuss tensions and change within the field. Consequently, by extending the condition of simultaneously existing polarities, Fielding's metaphor of bridging is the second vital condition for being at all able to understand and celebrate manifold. One way striving, solely for transformation and novelty, is in the long run is in danger of evaporation. We both need, want and are (material) substance also. A two way bridge can make meetings possible between substance and transformation, by letting substance transform as the transformation gains substance. Such bridging of polarities can bear the fruit of widening and innovative synergies that forward pluralistic understanding.

As I wrote this article, I was alerted through my email by the table of contents in the first issue of Qualitative Inquiry 2010. 'What a long strange trip it's been...' writes Yvonne 
Lincoln, tracking here her twenty-five years of qualitative and new paradigm research. According to Lincoln, our dialogues about the issue of rapport especially in the face of the " virtual tsunami of important critical work' (p.4) have never been more urgent, knowing that the ( American) National Research Council's has dismissed such work as not scientific: a ' silly piracy of the term science,' says Lincoln (2010, p.3). In other words, strong readings of what are the good and the bad divisions of research still seem to be at work on both sides here.

Lincoln ( 2010, p. 5) says further: 'I have a deep suspicion that one of the reasons some positivists hate us interpretivists so profoundly is that they cannot see what we are doing with research if there is not a cumulative function embedded in the paradigm(s)' She goes on to advocate that a potential cumulative function also should be addressed within constructivist and interpretivist research work. As positivist and interpretivist proponents:

'rarely talk to each other to see where there are useful linkages or enlightening junctures, $\ldots$ perhaps if we had some explicit and well-understood rules on how interpretivist and/or phenomenological inquiry provides cumulative knowledge - or cumulative understanding - we might have more fruitful dialogues, as well as being more systematically influential in political circles', Lincoln reflects (p. 6).

In deep respect for Lincoln's personal journey of tracking the history of qualitative research, I see interesting contours of an emerging bridge here, on which we can set about the healing of what Lincoln ( $p .8)$ calls 'the Enlightenment rift' between art and science, between mind and body, between reason and spirituality, between logic and emotion, and between technical rationality and human invention. I fully agree, and let her metaphor of healing sum up my points made above, that the identification of simultaneously existing polarities, extended with a search for possible bridging, is one substantial way of being dialogically critical and in motion.

\section{References}

Adler, P. A. and Adler, P. (1994) Observational techniques. I N.K. Denzin \& Y.S. Lincoln (eds) The Sage Handbook of Qualitative Research. Thousand Oaks, Ca.: Sage Publications, pp. 377-391.

Alvesson, M, and Sköldberg, K. (2009) Reflexive Methodology : New vistas for qualitative research. London: Sage.

Atkinson, P. A., Coffey, A. J. \& Delamont, S. (2001) A debate about our canon. Qualitative Research, 1(1): 5-20.

Atkinson, P. Coffey, A. and Delamont, S. (2003) Key Themes in Qualitative Research: Continuities and change. Walnut Creek, Ca.: AltaMira Press.

Denzin, N. K. and Lincoln, Y. S. (Eds.) (2005) The Sage Handbook of Qualitative Research ( $3^{\text {rd }} E d$.). Thousand Oaks, Ca.: Sage Publications. ( $1^{\text {st }} E d 1994 / 2^{\text {nd }} E d$ 2000.)

Denzin, N. K. and Lincoln, Y. S. (Eds.) (2008) The Landscapes of Qualitative Research. Thousand Oaks, Ca.: Sage Publications.

Drazin, A. (2009) Book review. Qualitative Research, 9(3): 383-385.

Fielding, N. G. (2009a) Going out on a limb: postmodernism and multiple method research. Current Sociology, 57(3): 427-447.

Fielding, N. G. (2009b) Of bridges and limbs: a response to Pascale and Healy. Current Sociology, 57(3): 462-465.

Gregory, M. (2009) Book review. Qualitative Research, 9(3): 388-389. 
Healy, P. (2009) The view from further out: a response to Fielding's 'Going out on a Limb': Postmodernism and multiple method research. Current Sociology, 57(3): 455-461.

Hoel, A. and Hvinden, B. (1982) Om bruk av gruppediskusjoner som samfunnsvitenskapelig forskningsmetode. (On the use of group discussions in research methods in the social sciences) In H. Holter \& R. Kalleberg (eds) Kvalitative metoder $i$ samfunnsforskning [Qualitative Methods in Social Science.] Oslo: Universitetsforlaget, pp-137-147.

Holter, H. and Kalleberg, R. (eds) (1982/1996/2002) Kvalitative metoder i samfunnsforskning [Qualitative Methods in Social Science]. Oslo: Universitetsforlaget.

Hughes, C. (2009) Book review. Qualitative Research, 9(3): 386-388.

Kincheloe, J. L. and McLaren, P. (2008) Rethinking critical theory and qualitative research. In N.K.

Denzin and Y.S. Lincoln (Eds) The Landscapes of Qualitative Research. Thousand Oaks, Ca.: Sage Publications, pp. 403-455.

Lincoln, Y. (2010) 'What a long strange trip it's been...': Twenty-five years of qualitative and new paradigm research. Qualitative Inquiry, 16(1): 3-9.

Løkken, G. (2000a) Toddler Peer Culture: The social style of one and two year old bodysubjects in everday interaction. PhD thesis. Trondheim: NTNU/Department of Education.

Løkken, G. (2000b) Using Merleau-Pontyan phenomenology to understand the toddler: toddler interactions in day care. Nordisk Pedagogik [Nordic Education Research] , 20(1): 13-23.

Løkken, G. (2008) Kvalitativ forskning - revolusjoner eller spenningsfylt kontinuitet? [Qualitative Research - revolutions or continuities of tension?] Lecture for a professorate in qualitative method at the Department of Education, NTNU, Trondheim.

Merleau-Ponty, M. (1962) The Phenomenology of Perception. London: Routledge and Kegan Paul.

Pascale, C.-M. (2009) Emerging landscapes in social research: comments on Nigel Fielding, postmodern thought and social research. Current Sociology, 57(3): 448-454.

Patton, M. Q. (1980) Qualitative Evaluation Methods ( $1^{\text {st }}$ Ed.). Beverly Hills, Ca.: Sage Publications.

Patton, M.Q. (1987) How to Use Qualitative Methods in Evaluation. Newbury Park, Ca.: Sage Publications.

Riessman, C. K. (1993) Narrative Analysis. Newbury Park, Ca.: Sage Publications.

Steinsholt, K. and Dobson, S. (eds) (2009) Verden satt ut av spill: postmoderne pedagogiske perspektiver [The World Put Out of Play: Postmodern perspectives in education.] Trondheim: Tapir Akademisk Forlag.

Van Manen, M. (1997). Researching Lived Experience: Human science for an action sensitive pedagogy. London, Ontario: The Althouse Press. 